\title{
Time to Invest in Primary Care Research-Commentary on Findings from an Independent Congressionally Mandated Study
}

\author{
John M Westfall, MD, MPH ${ }^{\top}$, Hope R. Wittenberg, MA ${ }^{2}$, and Winston Liaw, MD, MPH ${ }^{3}$ \\ 'Robert Graham Center for Policy Studies in Primary Care, Washington, DC, USA; ${ }^{2}$ Government Relations Council of Academic Family Medicine, \\ Washington, DC, USA; ${ }^{3}$ Department of Health Systems and Population Health Sciences, University of Houston, College of Medicine Building 2, \\ Houston, TX, USA
}

J Gen Intern Med 36(7):2117-20

DOI: $10.1007 / \mathrm{s} 11606-020-06560-0$

(c) Society of General Internal Medicine 2021

\section{CONGRESS WANTS TO KNOW ABOUT PRIMARY CARE RESEARCH}

Nearly half of all visits ${ }^{1}$ take place in primary care, and the majority of diseases and illnesses are managed within primary care without referrals to specialists and hospitals. ${ }^{2}$ Primary care research (PCR) is a crucial element in American health care that acknowledges the comprehensive and complex nature of primary care where patients are treated as whole persons in the context of a home, family, community, geography, and culture. At its best, PCR builds the unique evidence necessary for effective delivery of primary care. Despite this critical position, PCR is chronically underfunded. ${ }^{3}$ Similar to $\mathrm{PCR}$, the nation has underinvested in health services research (HSR), choosing to allocate resources to biomedical research rather than address the issues plaguing our system. HSR and PCR have the potential to establish the evidence base needed by policy makers, health system administrators, and patients to improve quality, safety, and effectiveness of health care in the United States.

The Agency for Healthcare Research and Quality was mandated $^{4}$ by congress to conduct a comprehensive study on Health Services Research and Primary Care Research. ${ }^{5}$ Congress wanted to know if their investment in HSR and PCR was worth it and to understand the funding landscape in light of the Administration's proposal to move AHRQ into the National

About the Authors

John $M$ Westfall is a family doctor and the Director of the Robert Graham Center for policy research in primary care and family medicine in Washington, DC. Dr. Westfall served on the RAND Study PCR technical expert panel. Winston Liaw is a family doctor, former Medical Director at the Robert Graham Center, and current Chair of the Health Systems and Population Health Sciences Department at the University of Houston College of Medicine. Hope Wittenberg is the Director of Government Relations for the Council of Academic Family Medicine.

Received July 24, 2020

Accepted December 22, 2020

Published online January 21, 2021
Institutes of Health (NIH). ${ }^{6}$ Specifically, the study included these 5 questions verbatim:

- What is the breadth and focus of federal agency research portfolios in HSR and PCR?

- What is the overlap among federal agency research portfolios and the coordination that occurs between federally funded HSR and PCR?

- What are the impacts of federally funded HSR and PCR and challenges to assessing and achieving impacts?

- What are the gaps in federally funded HSR and PCR and approaches to prioritizing gaps?

- What are options for improving the outcomes, value, and impact of future federally funded HSR and PCR?

\section{WHAT RAND DISCOVERED—PRIMARY CARE RESEARCH IS UNIQUE}

AHRQ contracted with the RAND Corporation ${ }^{7}$ to conduct the study and complete a comprehensive report that could be delivered back to Congress to inform federal policy decisions related to federal investment in in HSR and PCR. ${ }^{8}$ Initially considered a subset of HSR, it was quickly recognized that primary care research was a distinct research discipline, necessitating a comprehensive parallel analysis. Ultimately, the study undertaken considered HSR and PCR as unique research endeavors with some important similarities and synergies. The study included three core stage components. Two technical expert panels of about a dozen each, comprised of researchers, administrators, and patient or community members, were convened to advise the research team, provide input on the core questions, and inform the latter environmental scan. Additional interviews were conducted with 50 stakeholders representing researchers, state-level policymakers, delivery system leaders, federal research leaders, and other end-users of research including consumer groups and purchasers. Finally, a comprehensive literature scan was conducted to determine current federal research investment, publications, program reports, and other formal output from HSR and PCR. 


\section{DEFINITION OF PCR USED IN THIS STUDY}

Research on the provision of integrated, accessible health care services by clinicians who are accountable for addressing a large majority of personal health care needs, developing a sustained partnership with patients, and practicing in the context of family and community.

\section{DEFINITION OF HSR USED IN THE STUDY}

A multidisciplinary field of scientific investigation that studies how social factors, financing systems, organizational structures and processes, health technologies, and personal behaviors affect access to health care, the quality and cost of health care, and ultimately, our health and well-being.

Definitions were selected to provide a formal direction for all aspects of the study. The definition of $\mathrm{HSR}^{9}$ excludes some areas of research often considered health services research and conducted by HSR researchers such as research on social determinants of health that does not specifically examine their link to the delivery of health care. The PCR definition ${ }^{10}$ includes research areas contained in the legislative authorization of AHRQ, and its Center for Primary Care Research, as the statutory home for PCR.

Definition of HSR used in the study

A multidisciplinary field of scientific investigation that studies how social factors, financing systems, organizational structures and processes, health technologies, and personal behaviors affect access to health care, the quality and cost of health care, and ultimately, our health and well-being.

Definition of PCR used in this study

Research on the provision of integrated, accessible health care services by clinicians who are accountable for addressing a large majority of personal health care needs, developing a sustained partnership with patients, and practicing in the context of family and community.

\section{KEY FINDINGS FROM THE RAND STUDY}

It is beyond the scope of this commentary to report all the findings. Some items will be well known to health service and primary care researchers such as:

- The NIH may do some HSR and PCR but their focus is "very specific to body part, disease endpoints," while "AHRQ is more systems-focused," and "the way AHRQ conceptualizes it [PCR] is different than the way the NIH conceptualize."

- AHRQ is the only federal agency that has a congressional authorization to generate HSR.

- AHRQ also has a statutory charge to serve as the lead federal agency for primary care research (42 U.S.C. 299 et seq), although AHRQ has not received targeted appropriations for primary care research.

- Federal investments in HSR and PCR were calculated for each individual federal agency (NIH, AHRQ, CDC, etc.)
Fifty-seven percent of AHRQ projects were considered HSR and $13 \%$ were classified as PCR. Of 86,000 projects funded by NIH, $8 \%$ were considered HSR and less than $1 \%$ PCR. When totaled for all federal funders, just $9 \%$ of projects were health services research and $1 \%$ were primary care research though primary care is the place where most of the people get most of their care most of the time ${ }^{1,11}$.

- While some policy makers and agencies have worried about overlap in primary care research efforts, overlap in funding and topics was not found in this study. Given that just $1 \%$ of federally funded research is in primary care, one participant noted, "My impression is that the funding for primary care research. .. is so small that overlap is not an issue." Overlap with the Patient Centered Outcomes Research Institute (PCORI) was viewed as insignificant.

- Research impact often takes time to accumulate, complicating attribution to individual interventions, policies, programs, or funding streams. Because of chronic underfunding, many types of impact are just difficult to measure.

\section{THE SIGNIFICANCE OF THIS STUDY—GAPS IN PRIMARY CARE RESEARCH}

A core gap identified is a lack of research on the "basic science" of primary care. ${ }^{12}$ That is, "what's actually going on in primary care." This basic science of primary care is needed to understand the core functions of primary care, create and disseminate care models that deliver those functions, and engage patients to assure care is holistic and comprehensive. The 4 Cs of primary care ${ }^{13}$ : first contact, comprehensiveness, continuity, and coordination were mentioned but not universally accepted. As a core area of study, the basic science of primary care may help us understand how primary care leads to improved individual and population health outcomes. Another gap pointed out the need for rigorous research on how to engineer a primary care practice model that takes advantage of an expanded primary care workforce (advanced practice providers, behavioral health, etc.), advanced technology (EHRs, video/telehealth, wearables, and home monitoring devices), and the local geographic and cultural aspects of healthcare delivery.

While the report commented on a number of gaps in HSR and PCR, we believe there are many more facets to primary care research that are only alluded to or not mentioned at all:

- Clinical research-management of undifferentiated symptoms, care for patients with common conditions, care provided in primary care settings.

- Shared decision-making, treatment burden, and clinical tradeoffs for patients with complex medical conditions and multi-co-morbidities. 
- Methods for incorporating mental, emotional, and behavioral health into primary care practice and treatment models.

- Research that spans the sites of care where primary care clinicians provide care in ambulatory, ER, hospital, and long-term care facilities.

- Population health research on the patients and communities cared for by primary care clinicians. This includes the social determinants of health at the individual and community level (hotspots, ${ }^{14}$ coldspots ${ }^{15}$ ).

- Research on developing a robust PCR infrastructure. ${ }^{16}$ What is the best way to develop a cadre of primary care researchers with the teams and tools to address the basic science of primary care and the specific primary care issues noted above.

\section{RESEARCH GAPS THAT MIGHT HAVE MITIGATED OUR COVID-19 FAILURES}

There are research gaps included in this study that, if funded, might have mitigated aspects of our COVID-19 pandemic response, including racial and ethnic disparities for cases and deaths. ${ }^{17}$ The report mentions a few, but insufficient, studies on PCR or HSR health disparities funded by NIMHD. Rapid investments to eliminate these gaps now might help improve recovery efforts, and future response to similar health crises. Because the report was completed prior to COVID-19, these research gaps were not identified as COVID-19-specific. However, the report does call for research we believe could be crucial to COVID-19 response and recover:

- Research attention to the root causes of, and strategies for, addressing barriers to healthcare access.

- Effective interventions to address barriers to access, including telehealth and other strategies such as virtual visits and remote monitoring.

- There is a need to understand what can be done in primary care to address health equity.

- What are the patient-oriented primary care quality measures that would facilitate more engaged patient care?

- Measures for pediatric populations lag far behind measures for adult populations

\section{RECOMMENDATIONS AND THE META- MESSAGE-REAL FINDINGS AND URGENT NEEDS}

There are a number of formal recommendations in the report that we found most compelling to future PCR efforts, including:

- Maintain AHRQ as an independent agency within HHS to serve as the funding hub of federal HSR.

- Fund an entity to address the core primary care research needs and coordinate federal PCR efforts.
- Initiate a strategic planning process across federal agencies specifically dedicated to prioritizing PCR areas for funding investments.

- Provide targeted funding for a hub for federal PCR.

There are also several important meta-messages within the report. Primary care research is not the same thing or a subset of health services research. This has important implications for the funding for, organization of, and training in primary care research. Second, the evidence demands dramatically increased funding for primary care research, on an order of magnitude. Many states are mandating $10 \%$ spend on primary care. A federal $10 \%$ investment in primary care research is a good parallel step. Third, PCR needs an authorized and appropriated home. AHRQ has a statutorily mandated Center for Primary Care Research, but without explicit targeted funding from Congress, it has become a rather dormant National Center of Excellence in Primary Care Research, ${ }^{18}$ serving mainly as a clearinghouse of primary care tools developed by AHRQ. The RAND Study does not include a specific recommendation for an amount of funding. It does recommend a coordinating center for primary care research. That is not enough. This report provides ample evidence that it is time to truly invest in PCR. Either it is time to fund a PC Center at AHRQ and reinvigorate our efforts to "billionize" AHRQ, or it is time to recognize PCR may belong alongside the disease- and organ-specific research institutes at the NIH as an appropriated National Institute for Primary Care Research or a P50 Center. While a crosscutting entity at the NIH performs a similar function for emergency care research, ${ }^{19}$ there is no analogue for primary care, contributing to a lack of funding within the NIH. The RAND Study on Health Services and Primary Care research should not be just another book on the shelf that has no impact. Coupled with the profound COVID-19 response failure of our health system, this report provides the evidence for building a new PCR infrastructure. Immediate funding for PCR can help us recover from COVID-19, plan for the next pandemic, and address most of the healthcare problems faced by most of the people, most of the time.

Corresponding Author: John M Westfall, MD, MPH; Robert Graham Center for Policy Studies in Primary Care, Washington, DC, USA (e-mail: Jwestfall@aafp.org).

\section{Compliance with Ethical Standards:}

Conflict of Interest: Dr. Westfall served on the RAND study Primary Care Research Technical Expert Panel. No other conflicts declared.

\section{REFERENCES}

1. Petterson S, McNellis R, Klink K, Meyers D, Bazemore A. The State of Primary Care in the United States: A Chartbook of Facts and Statistics. January 2018 https://www.graham-center.org/content/dam/rgc/ 
documents/publications-reports/reports/PrimaryCareChartbook.pdf. Accessed 9.16.2020

2. Franks P, Clancy C. Referrals of adult patients from primary care: demographic disparities and their relationship to HMO insurance. J Fam Pract. 1997 Jul;45(1):47-53.

3. Cameron BJ, Bazemore AW, Morley CP. Lost in Translation: NIH Funding for Family Medicine Research Remains Limited. J Am Board Fam Med 2016; 29:528 -530.

4. Health Services and Primary Care Research Study. https://www.ahrq. gov/healthsystemsresearch/hspc-research-study/index.html. Accessed 10.17.20.

5. Mendel P, Gidengil CA, Tomoaia-Cotisel A, Mann S, Rose AJ Leuschner KJ, Qurishi NS, Kareddy V, Sousa J, Kim D. Health Services and Primary Care Research Study Comprehensive Report. RAND Corporation, Santa Monica, Calif. https://www.ahrq.gov/sites/ default/files/wysiwyg/healthsystemsresearch/healthsystemsresearch. pdf. Accessed 10.17.2020.

6. Bindman A, Moving AHRQ Into the NIH: New Beginning or Beginning of the End. Health Affairs Blog. March 27, 2017. https://doi.org/10.1377/ hblog20170327.059384. https://www.healthaffairs.org/do/10.1377/ hblog20170327.059384/full/. Accessed 9.17.2020.

7. About the RAND Corporation. https://www.rand.org/about.html. Accessed 9.17.2020.

8. Khanna G. Maximizing the Impact of Federally Funded Health Services Research and Primary Care Research. Agency for Healthcare Research and Quality. https://www.ahrq.gov/news/blog/ahrqviews/impact-ofhsr-pcr.html. Accessed 9.17.2020.

9. Lohr KN, Steinwachs DM. Health Services Research: An Evolving Definition of the Field. HSR: Health Services Research 37:1 (February 2002). https://www.ncbi.nlm.nih.gov/pmc/articles/PMC1430351/pdf/ hesr_01020.pdf. Accessed 9.17.2020.

10. Institute of Medicine 1996. Primary Care: America's Health in a New Era Washington, DC: The National Academies Press. https://doi.org/10. 17226/5152. file:///C:/Users/jwestfall/Downloads/5152\%20(1).pdf. Accessed 9.17.2020.
11. Green LA, Fryer GE, Yawn BP, Lanier D, Dovey SM. The Ecology of Medical Care Revisited. N Engl J Med 2001; 344: https://doi.org/10. 1056/NEJM200106283442611.

12. Primary Care Research: Its Unique Role in Health Care. Council of Academic Family Medicine https://stfm.org/media/1664/cafm-primarycare-research-unique-role.pdf. Accessed 9.17.2020.

13. Donaldson $\mathbf{M S}$, Yordy $\mathbf{K D}, \mathbf{L o h r} \mathbf{K N}$, et al., editors. Primary Care: Americas Health in a New Era. Institute of Medicine (US) Committee on the Future of Primary care. Washington (DC): National Academies Press (US); 1996.

14. Healthcare Hotspotting. A project of the Camden Coalition of Healthcare Providers. https://hotspotting.camdenhealth.org/. accessed 9.17.2020.

15. Westfall JM. Cold-Spotting: Linking Primary Care and Public Health to Create Communities of Solution. J Am Board Fam Med 2013;26:239 240. https://www.jabfm.org/content/jabfp/26/3/239.full.pdf. Accessed 9.17.2020.

16. Liaw W. Bazemore AW, Ewigman B, Turin TC. McCorry D. Petterson S, Dovey SM. Advancing bibliometric assessment of research productivity: an analysis of US Departments of Family Medicine J Prim Health Care 2020;12(2):149-158. doi:https://doi.org/10.1071/HC19098.

17. Hooper MW, Napoles AM, Perez-Stable EJ. COVID-19 and Racial/ Ethnic Disparities. JAMA. 2020;323(24):2466-2467. https://doi.org/10. 1001/jama.2020.8598

18. National Center for Excellence in Primary Care Research (NCEPCR). Agency for Healthcare Research and Quality. https://www.ahrq.gov/ ncepcr/index.html. Accessed 9.17.2020.

19. Office of Emergency Care Research. National Institutes of Health. https://www.ninds.nih.gov/Current-Research/Trans-Agency-Activities/ Office-Emergency-Care-Research. Accessed 9.17.2020.

Publisher's Note: Springer Nature remains neutral with regard to jurisdictional claims in published maps and institutional affiliations. 